\title{
The use of positive and negative appeals in social advertising: a content analysis of television ads for preventing HIV/AIDS
}

\author{
Beatriz Casais $^{1}$ (D) . João F. Proença $a^{2,3}$
}

Received: 23 September 2020 / Accepted: 10 October 2021 / Published online: 23 October 2021

(c) The Author(s), under exclusive licence to Springer-Verlag GmbH Germany, part of Springer Nature 2021

\begin{abstract}
Effectiveness of positive and negative appeals in social advertising depends on the target audience and the context in which the messages are applied. However, there is a dearth of research on the real use of such message appeals by social marketers. Considering the importance of practice theory in social marketing, this paper presents a longitudinal research on the use of positive and negative appeals in social advertising, since communication has been particularly relevant in social marketing practices over time. A content analysis of 375 HIV/AIDS-prevention TV ads from four European countries indicates that positive appeals had expressive and higher proportional use over the entire period under analysis. The researchers identified positive appeals, especially in rhetoric, music and voice tonality, while negative appeals are more prevalent in narratives and signs from the scenes. The results show that participation of public figures promoting coping response was low, but increasing over time. Negative appeals are mostly expressed in countries with higher uncertainty avoidance indexes and higher epidemic incidence rates. The prevalence of positive and negative appeals in social advertisements informs about practitioners' choices when designing campaigns and allows analyzing congruity between the use of appeals and theoretical recommendations for social marketing effectiveness. The study opens the discussion about the application of social marketing theories into practice and how the analysis of social marketing practices may contribute to design innovative theoretical approaches, particularly regarding a topic plagued by inconsistent findings in the literature on message-frame effectiveness in social marketing. The practitioners' preference for the gain-frame perspective over the protection motivation approach allows inquiring about the motivations and constraints leading to that choice.
\end{abstract}

Keywords Positive appeals $\cdot$ Negative appeals $\cdot$ Social advertising $\cdot$ Health promotion $\cdot$ HIV prevention

Beatriz Casais

bcasais@eeg.uminho.pt

Extended author information available on the last page of the article 


\section{Introduction}

Social marketers encourage individual compliance via message appeals in social advertising. The message frames may have a positive or negative appeal, according to the intention of induce behaviours, and an informational or emotional tone, depending on the influence of cognition or emotions among the target audiences (Brennan \& Binney, 2010; Helmig \& Thaler, 2010; McKay-Nesbitt et al., 2011).

Positive appeals aim to show the direct benefits and gains of behaviour change. Negative appeals describe losses and unintended consequences of certain attitudes and behaviours by creating psychic discomfort (Brennan \& Binney, 2010). This distinction follows the assumptions of Prospect Theory (Kahneman \& Tversky, 1979; Tversly \& Kahneman, 1981), which considers the existence of gain-framed and lossframed messages that affect risk-seeking and risk-averse attitudes (Kahneman \& Tversky, 1979; Rothman et al., 1993; Tversly \& Kahneman, 1981).

The analysis of message strategies that work better in public health is a research challenge (Evans \& McCormack, 2008) in terms of finding viable paths to reach social marketing success. This has been an important research aiming at perceiving the most effective strategy to promote behaviour change (). Some authors have reported the advantages of negative appeals using fear and threat messages that explore the loss-frame of social change (Charry \& Demoulin, 2012; Gallopel-Morvan et al., 2009; Garg et al., 2021; Hartmann et al., 2014; Muralidharan \& Sheeham, 2017). Others advocate the effectiveness of positive appeals regarding persuasiveness, which activate the gain-frame perspective for attitude and behaviour change (Gantiva et al., 2021; Hornik et al., 2017; Previte et al., 2015; Ruiter et al., 2014; Shin et al., 2017; Teng et al., 2019b). The state of the art shows inconsistent findings on the effectiveness of positive and negative appeals in social marketing (Robbins \& Niederdeppe, 2019), but the literature agrees that recipient mood (Anghelcev \& Sar, 2014), target audiences' risk perceptions and their perceived self-efficacy to change are influencing variables in social marketing success (Cheng et al., 2011).

As a parallel research on effectiveness, the study of social marketing practices is also relevant to contribute to theoretical discussions, under the assumption of a practice-theoretical intervention planning process applied to social change (Spotswood et al., 2017). Understanding how messages are created and whether they follow (or not) the theoretical findings on the most effective message frame for each context and target audience allows a step forward in comprehending social marketing interventions and their effectiveness control. Also, as the state of the art on the effectiveness of positive and negative appeals is inconsistent and contradictory, even showing that the message frame does not significantly differ regarding the persuasiveness of charity advertising (Xu \& Huang, 2020), the analysis about the use in practice of message frames may contribute to the discussion of the topic.

There are few studies on the application of social advertising appeals in practice. A study has analysed the prevalence of emotional and rational tone in social advertisements (Casais \& Pereira, 2021), highlighting the expressive use of rational tone. Regarding the direction of appeals, those that have been done reflect the predominance of negative appeals, but consist on meta-analysis of the 
literature, instead of a research based on a sample database (Hastings et al., 2004; Slavin et al., 2007). The literature has failed to address the appropriateness of social marketing policies to their specific context, which has been highlighted by several authors as an important challenge (Andreasen, 2002; Grassly et al., 2001; Grier \& Kumanyika, 2010; Hankins \& Zalduondo, 2010; Likatavicius \& VandeLaar, 2012; Vega \& Roland, 2005). The analysis of the fit between previous evidences of effectiveness in theory and the application of those recommendations into practice by framing the most effective direction of appeal to each situation may help to resolve the theoretical inconsistencies. Filling in these knowledge gaps in the state of art is essential, considering that theory is based on the analysis of practice (Bourdieu, 1977, 1990; Reckwitz, 2002).

Theories and practices should consider population heterogeneity and contextual specificities, and it is important to research what marketing managers do in public policy and how public marketing is done (Ronald Paul Hill \& Martin, 2014). Communication has been a very important component within social marketing programmes, and social advertising on television is one of the most widely used communication tools in the field (Abroms \& Maibach, 2008; Block \& Keller, 1995; Griffin \& O'Cass, 2004; Hastings \& Haywood, 1991; Mattson \& Basu, 2010). This study aims at analysing the prevalence of positive and negative emotional appeals used in the practice of health communication. This research proposes to analyse the practice of management decisions based on the evidence about what are the most prevalent appeals used, according to the direction of messages, when they are used and how they are manifested in different situations. This allows discussing whether positive and negative appeals fit the conditions that interfere in the effectiveness of appeals according to the literature review: target audiences, messages, type of institutional sources, cultural and political context, health situation in terms of the seriousness of the epidemic dynamics (Gygax et al., 2010; Self \& Findley, 2010; Tan \& Cho, 2019). To contribute to the topic of the direction of social marketing appeals, this study adopts the practice theory approach to firstly identify the practitioners' options regarding the use of positive and negative appeals and subsequently to discuss the theoretical implications of those evidences.

To achieve this purpose, three research questions were formulated to meet the knowledge gap found in the literature review:

- Research Question 1 (RQ1): What is the prevalence of positive and negative appeals in social advertising?

The answer may be compared with findings in the literature and may also give an indication about the gap between theory and practice (Quinn et al., 2010; Silva \& Silva, 2012). This question also allows an understanding of whether appeals are used in combination as proposed in the literature (Cho \& Salmon, 2007; Gallopel-Morvan et al., 2009; Witte, 1992; Witte \& Allen, 2000).

- Research Question 2 (RQ2): When have positive and negative appeals been used in social advertising over time?

This question allows understanding whether positive and negative appeals are used in alternate cycles because of overuse of both directions and their weakness 
or ineffectiveness caused by saturation (Brennan \& Binney, 2010; Hastings et al., 2004; Slavin et al., 2007).

- Research Question 3 (RQ3): How have positive and negative appeals been used in social advertising?

With this question, the researchers seek to show evidence on how those appeals are manifested in social advertising, thus contributing to their future identification, and discuss whether the context where they are applied fits with the context where the literature shows each appeal to be more effective.

In order to identify and characterise positive and negative appeals, the researchers conducted content analysis of social ads. The paper presents a longitudinal research on the use of positive and negative appeals in 375 social advertisements for a serious and discriminated disease, HIV/AIDS infection, in four European countries - France, Germany, Italy and Portugal. The study also identifies how positive and negative appeals are manifested in social ads and considers contextual data to discuss the use of both appeals by practitioners.

Stereotypes created at the beginning of infection, proclaiming that HIV was a disease of promiscuous people, has possibly not led individuals to experience fear of transmission and might have prompted non-acceptance of preventive messages (Campbell \& Babrow, 2004). At the same time, the low risk perception due to lack of awareness about HIV (Hachfeld et al., 2015), and the low literacy about HIV transmission (Palumbo, 2015) have relevant implications in the population's response to health promotion activities (Li et al., 2004). In fact, self-perceived health risk is an important variable of the Health Belief Model, which identifies the drivers for health-related social change (Rosenstock, 1974). On the other hand, scaring the already scared people may accentuate the existing stigma and discrimination towards the most vulnerable populations, such as men who have sex with men, sex workers, or drug users, as well as people living with HIV (Muthusamy et al., 2009). This fact may create trade-offs for social marketers when deciding the strategy of positive or negative emotional appeals in prevention messages. A better understanding of practice regarding this topic may be an important contribution to social marketing theory (Quinn et al., 2010). The empirical evidence may also identify gaps in the translation of social marketing theory into practice (Levit \& Cismaru, 2020). Considering that social advertising is an important communication tool of social marketing, the topic has contextual implications for policy, socioeconomic and cultural appropriateness of social marketing practice (Tan \& Cho, 2019), and also provides evidences for social marketing history (French, 2015).

\section{Conceptual Background}

\subsection{Negative and Positive Appeals in Social Advertising}

Social advertising may express social change with positive or negative appeals (Brennan \& Binney, 2010). Positive appeals aim to show the direct benefits and gains of behaviour change as an incentive. Negative appeals describe losses and 
unintended consequences of certain attitudes and behaviours by creating discomfort. In order to inhibit people from continuing or adopting certain unhealthy behaviours, social marketers use negative messages with threats to create viewer reactions of fear, guilt or shame that lead to a disincentive to behave in a certain way (Boudewyns et al., 2013; Brennan \& Binney, 2010; Cauberghe et al., 2009; Floyd et al., 2000). On the contrary, positive appeals aim to show the gain-frame, with the benefits of behaviour change, as an incentive to adopting a specific behaviour (Buyucek et al., 2019; Lewis et al., 2007; O’Keefe \& Jensen, 2008).

This dichotomy of message frames affects the response to social change based on the perceived risk, in accordance with Prospect Theory (Kahneman \& Tversky, 1979), which states that people respond differently to risks depending on how messages are framed - in positive or negative directions. This theory has been adopted in social marketing, considering that the individual processes a balance between the possible loss and the possible gain when taking a health risky behaviour (Helmig \& Thaler, 2010; L. W. Jones et al., 2003), which is affected by risk-seeking and riskaverse attitudes. The result of this balance between health gains and losses depends on target vulnerability and perceived self-efficacy to change, which is directly connected to the social marketing segmentation perspective (Rimal et al., 2009) and the Health Belief Model (Rosenstock, 1974), a theoretical framework that designs the drivers for health-related social marketing.

Protection Motivation Theory (PMT) suggests that the direct cause of persuasiveness is our ability to perceive the severity of a threat, our perception of vulnerability and our perceived self-efficacy to change behaviours at low cost (Prentice-Dunn \& Rogers, 1986). The Extended Parallel Processing Model (EPPM) (Witte, 1994) later included the explanation that low-efficacy perceived messages may lead to defensive reactions by fear control. Fear control or maladaptive coping responses are defensive reactions to fear appeals that result in unintended consequences, such as the boomerang effect (Cho \& Salmon, 2007; Good \& Abraham, 2007). To prevent this problem, PMT and EPPM suggest combining negative appeals with positive appeals (Gallopel-Morvan et al., 2009), which is supported by Ordered Protection Motivation Theory (OPM) (Eppright et al., 2003), by promoting coping responses after threat appraisals. For example, the combined use of humour with threat appeals may decrease the defensive response to fear and increase its effectiveness (Mukherjee \& Dubé, 2012; Myrick \& Oliver, 2015; Yoon \& Tinkham, 2013).

Using fear and threat, PMT and EPPM have been widely used to help create social marketing actions and several researchers demonstrate their effectiveness for creating persuasiveness in a variety of health contexts (Charry \& Demoulin, 2012; Dickinson-Delaporte \& Holmes, 2011; Garg et al., 2021), generating both positive and negative feelings (Gomes \& Casais, 2018). Other authors claim that fear control does not necessarily undermine the effectiveness of a threat appeal, but can also lead to its acceptance by moderating fear levels (Cauberghe et al., 2009). As negative appeals have been popular in social marketing communication (Antonetti et al., 2015), we infer a preponderance of threat appeals in practice.

However, recent literature has been defending positive appeals (Hornik et al., 2017; Previte et al., 2015; Ruiter et al., 2014; Shin et al., 2017; Teng et al., 2019b) as an alternative to overuse and saturation of negative appeals (Brennan \& Binney, 
2010). For example, the gain-frame has been considered more effective to deal with Covid-19 (Gantiva et al., 2021). Positive emotional appeals are based on humour, irony, hope, portraying benefits and using celebrities or social models to activate the coping response (Hastings et al., 2004; Lewis et al., 2007). Although contradicting Garg et al.'s findings (2021), other authors highlight that positive appeals show effectiveness regarding health behaviours over longer periods of time, by increasing perceptions about the expected benefits (Chiang et al., 2018; O'Keefe \& Jensen, 2008). Positive appeals have the advantage of encouraging people to behave in a certain way by a sense of empowering through change (Buyucek et al., 2019; Wang et al., 2020). Another advantage is the decrease of stigma and discrimination associated with illness or high-risk populations by not showing shocking images. The use of positive appeals in health-related social marketing may reduce traumatic symptoms in people who have already suffered from the diseases in question (Lewis et al., 2007; Slavin et al., 2007).

\subsection{Factors Influencing the Efficacy of Positive and Negative Appeals}

Although there are evidences of effectiveness of positive and negative appeals in different contextual situations and regarding different targets, conclusions as to whether positive or negative directions are best for persuasive message appeals remain contradictory even when the cause is the same (Hastings et al., 2004; Robbins \& Niederdeppe, 2019; Zhao \& Pechmann, 2007), which stresses the relevance of research that examines the real use of such appeals. Some authors (S. C. Jones \& Owen, 2006; Vos, Crouch, Quester, \& Ilicic, 2017) suggest differentiating their use according to different situations where each direction is the most appropriate (Chen, 2016; Keller \& Lehmann, 2008). Positive and negative emotional appeals may be tools for changing behaviours in different situations (Cheng et al., 2011; Henley \& Donovan, 1999; S. C. Jones \& Owen, 2006). Different responses depend on individual motivation or self-regulation to change (Brennan \& Binney, 2010; Gygax et al., 2010; Hastings et al., 2004; Keller \& Lehmann, 2008; Self \& Findley, 2010; Zhao \& Pechmann, 2007), as well as on the level of perceived message response efficacy (Block \& Keller, 1995; Meyerowitz \& Chaiken, 1987). The effectiveness of positive or negative appeals is related to perceived risk (Cooper et al., 2014; Rothman et al., 1993; Sar \& Anghelcev, 2013), which varies according to the level of awareness of the seriousness of consequences and the level of vulnerability to the problem (Cooper et al., 2014; Rothman et al., 1993; Ruiter et al., 2004). The effects on persuasion are connected to the Regulatory Focus Theory (Higgins, 1997, 1998) and depend on the target's level of motivation, which is segmented by demographic factors, the level of efficacy of the recommended behaviour, and the perceived selfefficacy to adopt it (Cooper et al., 2014; Keller, 2006; Keller \& Lehmann, 2008; Zhao \& Pechmann, 2007). Recipient mood is also considered an important variable (Anghelcev \& Sar, 2014).

Besides appropriateness to target audiences, the type of messages and the seriousness of the disease, cultural context is also an important topic for consideration in the design of marketing appeals, both in commercial and social marketing 
(Airhihenbuwa \& Obregon, 2000; Chan et al., 2007; Hastings et al., 2004; Laroche et al., 2001; Orth et al., 2007; Vincent \& Dubinsky, 2005). Context also influences the effectiveness of positive and negative emotional appeals (Reardon et al., 2006; Rothman et al., 1993). Strategies for the direction of message appeals may reflect conservative or progressive political philosophies (Green \& Witte, 2006; Hastings et al., 2004), since social marketing per se plays a political role in achieving certain goals (Cho \& Salmon, 2007; Raftopoulou \& Hogg, 2010). Acceptance of messages influences the reputation and image of sponsored organisations (Hastings et al., 2004). Negative appeals, by exaggerating the dangerous consequences of a given behaviour, reflect badly on a government's reputation when sponsored by the public sector, for example (Hastings et al., 2004).

\subsubsection{Regulatory Focus Theory}

Effectiveness of positive or negative appeals is related to regulatory focus theory and depends on recipient mood (Anghelcev \& Sar, 2014) and their level of motivation, which is segmented by demographic factors, the efficacy level of the recommended behaviour and the perceived self-efficacy to adopt it (Cooper et al., 2014; Pounders et al., 2018). Negative appeals are more effective when subjects are motivated to process the message, as prevention-focused people do (Gygax et al., 2010; Self \& Findley, 2010), as is the case of elderly females (CangelosiJr., Ranelli, \& Markham, 2009; Keller \& Lehmann, 2008; Noble et al., 2014). Negative appeals are only effective under high-efficacy conditions, which only happens with threat (Peters et al., 2013). Positive appeals are especially effective when subjects are not motivated to process the message (Block \& Keller, 1995). Those in greatest need of changing behaviours may be the most likely to exhibit fear control and the least motivated to responding with behavioural changes when exposed to health messages using negative appeals. That is why positive appeals are advised when targeting promotionfocused people - usually young males, who are more likely to engage in unhealthy risk behaviours (Gygax et al., 2010; Self \& Findley, 2010).

\subsubsection{Sensitivity to Context}

Health communication should also fit with the culture and epidemiologic appropriateness of the targeted country (Tan \& Cho, 2019). For example, adolescents from cultures with high uncertainty avoidance respond more favourably to negative than positive appeals in antismoking messages (Reardon et al., 2006). Negative appeals in health-related social marketing sponsored by the public sector tend to reflect badly on a government's reputation, and the disclosure of exaggerated negative consequences has been shown to result in discrediting (Hastings et al., 2004). The source is not implicated in the effectiveness of positive appeals (Shin et al., 2017).

The literature also proposes the adaptation of social marketing policies to the context of the related causes and the epidemic dynamics (Casais \& Proença, 2018; Grassly et al., 2001). In the case of positive and negative appeals, the literature establishes a relationship between the effectiveness of fear and disease severity in the danger control process (Cooper et al., 2014; Ruiter et al., 2004). This means 
that if negative appeals are more shocking messages and positive appeals are less discriminating, it is expected that if the research verifies an oscillation between both appeals, it should fit with epidemic dynamics, in addition to other situational contexts.

The analysis of the fit between previous evidence of effectiveness in theory and application of those recommendations into practice may help to resolve the theoretical inconsistencies and gives an understanding about where changes in the management of this matter should be firstly and more intensively implemented. This research proposes the analysis of the use of positive and negative emotional appeals and how they are manifested and are differently applied, since it is important to identify the appropriateness of practice to social marketing theory (Cook et al., 2020). On the other hand, it is highly relevant to understand the transition of social marketing theories into practice (Levit \& Cismaru, 2020). A better understanding of social marketing practices and their fit with the context may contribute to improve future analysis on the effectiveness of social marketing appeals and justify future research about the motivations and constrains for the choice of appeals in practice. In this sense, the authors conducted a longitudinal study on the use of positive and negative emotional appeals in health-related social advertising, since it is an important communication tool of the social marketing mix.

\section{Methods}

This research focuses on the use of positive and negative appeals in healthrelated social advertising. A longitudinal study on the use of positive and negative emotional appeals in health-related social marketing may identify different realities, such as different events in the history of diseases, different clinical developments, physical or social impacts and costs of change that influence perceived self-efficacy. Choosing a single case that uses a high level of threat and shows an outcome of death, for example, is needed, even though the results will be confined to that context. At the same time, it should agree with the observation of the unintended effects of that threat, such as illness-related stigma (Lewis et al., 2007; Slavin et al., 2007). HIV/AIDS in Europe is a good example for the research of the defined purpose, since it is a serious and discriminated disease targeted at different segments via different messages (Noar et al., 2009). Social advertisements for HIV prevention have been reactive to epidemic dynamics (Casais \& Proença, 2018), and also reveal contradictory results about the effectiveness of direction appeals (Lwin et al., 2010; Muthusamy et al., 2009; Smerecnik \& Ruiter, 2010; Terblanche-Smit \& Terblanche, 2010). The stereotypes created at the beginning of the infection, proclaiming that HIV is a disease of promiscuous people, may have led individuals to not experience fear of transmission, which might have prompted preventive messages acceptance (Campbell \& Babrow, 2004). This is also a health topic lacking awareness among the citizens (Hachfeld et al., 2015; Li et al., 2004; Palumbo, 2015) and subject to stigma and discrimination towards the most vulnerable populations (Muthusamy et al., 2009). This fact may create trade-offs for social marketers when deciding the strategy of positive or negative emotional appeals in prevention messages. 
Moreover, the history of the disease is in this case particularly relevant for research, because since the introduction of anti-retroviral treatments (ART), AIDS became a chronic disease, with preponderance in prevention campaigns, due to changes in the perceived health severity (Slavin et al., 2007).

\subsection{The Database}

The research is focused on television advertisements, since communication has been an important technique of the social marketing mix in health issues, even in the era of the internet (Precourt, 2017). The study focuses on a database of 375 HIVprevention advertisements extracted from a wider database of 539 television social advertisements on HIV/AIDS prevention collected from 21 EU countries and developed by governments and/or NGOs and broadcast on TV since the initial diagnosis of the infection in 1981 to the end of 2011. This period comprises the first thirty years of the epidemic, before it started to decline worldwide. We selected all the ads from four countries, which represented $69.6 \%$ of the database, so that we could conduct a consistent longitudinal research. The database includes 146 ads from France (38.9\%), 115 from Germany (30.7\%), 76 from Portugal (20.3\%), and 38 from Italy $(10.1 \%)$. The selected data were broadcast between 1986 and 2011. The database considers all the HIV-prevention TV ads found in video sharing websites and social networks. Data collection was conducted online, considering the amount of institutional social ads shared on a daily basis on video sharing websites and social networks (R. P. Hill \& Morgan, 2011; Paek et al., 2010; Spigel, 2009).

The database was built filling in the benchmark criteria for social marketing recommended in the literature: implicit exchange theory and competition perspective, focus on behaviour change, audience research and segmentation (French \& Russell-Bennett, 2015; Wettstein \& Suggs, 2016).

\subsection{Data Analysis}

The narratives of the social advertisements were translated from their original languages to English with the support of native speakers or long-term residents. Contextual aspects of the advertisements such as the use of famous songs, national symbols or metaphors and the endorsement of national celebrities were considered. The coding process considered the description of the characters, music, colours, nonverbal symbols, story review and type of rhetoric of each advertisement. These notes were recorded by the researchers in NVivo software.

The data was coded by the two authors according to country and year of broadcast, and source - government, NGO or a partnership of both. The behaviourchanging messages identified and the main targets were also coded. The interjudge agreement between the two researchers was obtained for the entire sample. The last two categories mentioned implicated the use of the Proportional Reduction in Loss (PRL) approach to calculate reliability of that coding (Rust \& Cooil, 1994). With four judges - three external experts in marketing and communication and the researchers coding -,the agreements were calculated between the six groups 
of judges for coding a sample of twenty advertisements composed of five ads from each country. There was interjudge agreement on $84.2 \%$ of the sample for the target coding process, and $97.5 \%$ for coding behaviour change messages. This result corresponds to a PRL reliability of 0.99 and 1, respectively. The positive and negative appeals of the advertisements were also coded, following the content analysis model of Casais and Proença (2015), which is focused on the story concept of the ads and the verbal and non-verbal signs (see Fig. 1). This model is the result of an extensive research of social marketing literature on the definition of positive and negative appeals and how they are manifested in social advertisements. The PRL reliability of that model was calculated, with $79.1 \%$ intercoding agreement in the classification of a sample of twenty social advertisements. This result corresponds to a PRL reliability of 0.97 concerning the four judges. The discrepancies were resolved by debating the judges' arguments.

The researchers coded the transcriptions or notes corresponding to positive or negative appeals in each of the eight categories of the model regarding their contextual interpretation. Considering the number of references coded in each category for each appeal, the researchers classified those categories as positive or negative or even a combination of both. The final classification of the advertisement might be positive, negative or a combination of both, depending on the proportion of classifications in the eight categories. A social ad was only classified as a combination of appeals if there were an equal number of categories classified as positive, negative and/or a combination of both.

The use of positive and negative appeals is described by year of broadcast and country. In order to understand how positive and negative appeals have been used, the researchers analysed the presence of appeals in the categories of the advertisements, as well as their contribution to the final classification of the ads. The influencing factors in each observation were analysed by comparing the classification of appeals with the efficacy levels of the message response and target motivation, according to regulatory focus theory and demographic factors that characterize it. A longitudinal analysis of results was also conducted by type of source organization and country, because of the influence of culture and public policies in appeal direction effectiveness (Reardon et al., 2006) and the importance of cultural appropriateness in health communication (Tan \& Cho, 2019). The researchers also performed a correlation analysis between the use of appeals and epidemic incidence rates. The heterogeneity of country databases did not allow a comparison between countries.

\section{Results}

\subsection{Longitudinal Prevalence of Positive and Negative Appeals in Social Advertising}

The results show that positive appeals have an expressive use in social advertising for HIV/AIDS prevention in France, Germany, Portugal and Italy. Table 1 shows the frequency of advertisements classified as positive, negative and a combination of both appeals. 


\begin{tabular}{|c|c|}
\hline \multicolumn{2}{|c|}{ Story Concept } \\
\hline Positive & Negative \\
\hline $\begin{array}{c}\text { Benefits of intended behaviors } \\
\text { (Brennan and Binney 2010; Cauberghe et al. } \\
\text { 2009; Hastings et al. 2004; Lewis et al 2007; } \\
\text { Lewis et al. 2009) }\end{array}$ & $\begin{array}{l}\text { Dangerous consequences of unintended } \\
\text { behaviors (Biener et al. 2004; Brennan and } \\
\text { Binney 2010; Cauberghe et al. 2009; Hastings et } \\
\text { al. 2004; Lewis et al. 2007; Lewis et al. 2009) }\end{array}$ \\
\hline \multicolumn{2}{|c|}{ Verbal Communication (oral/written) } \\
\hline \multicolumn{2}{|c|}{ Words/Expressions used in the narrative } \\
\hline Positive & Negative \\
\hline $\begin{array}{l}\text { Life, health, smile, love, respect, protect, } \\
\text { prevent, treat, good, responsibility, copy, } \\
\text { save, gains, intended, efficacy (Dillard and } \\
\text { Anderson 2004; Hastings et al. 2004; Lewis et } \\
\text { al. 2007; Lewis et al. 2009) }\end{array}$ & $\begin{array}{l}\text { Death, disease, illness, danger, fatality, fear, } \\
\text { guilt, shame, risk, losses, bad, consequences, } \\
\text { threat, effects, unintended (Brennan and } \\
\text { Binney 2010; Cauberghe et al. 2009; Dillard and } \\
\text { Anderson 2004; Hastings et al. 2004) }\end{array}$ \\
\hline \multicolumn{2}{|c|}{ Slogan } \\
\hline Positive & Negative \\
\hline Incentive (Dillard and Anderson 2004) & Disincentive (Dillard and Anderson 2004) \\
\hline \multicolumn{2}{|c|}{ Rhetoric Figures } \\
\hline \multicolumn{2}{|l|}{ Positive } \\
\hline $\begin{array}{l}\text { Humor, irony, empathy, motivating, } \\
\text { advising, copy response (Dillard and } \\
\text { Anderson 2004; Hastings et al. 2004; Lewis et } \\
\text { al. 2007; Lewis et al. 2009) }\end{array}$ & $\begin{array}{l}\text { Shame, Frightening, Suspense with fear } \\
\text { (Brennan and Binney 2010; Cauberghe et al. } \\
\text { 2009; Dillard and Anderson 2004; Hastings et al. } \\
\text { 2004) }\end{array}$ \\
\hline \multicolumn{2}{|c|}{ Non-Verbal Communication } \\
\hline \multicolumn{2}{|c|}{ Tonality of Voice / Music } \\
\hline Positive & Negative \\
\hline
\end{tabular}

\begin{tabular}{|c|c|}
\hline $\begin{array}{l}\text { Motivating, exciting, empathic (Dillard } \\
\text { and Anderson 2004; Hastings et al. 2004; } \\
\text { Lewis et al. 2007; Lewis et al. 2009) }\end{array}$ & $\begin{array}{l}\text { Frightening, sad, noisy, threatening } \\
\text { (Brennan and Binney 2010; Cauberghe et al. } \\
\text { 2009: Dillard and Anderson 2004; Hastings et al. } \\
\text { 2004) }\end{array}$ \\
\hline \multicolumn{2}{|r|}{ Colors } \\
\hline Positive & Negative \\
\hline $\begin{array}{l}\text { Varied palette, blues, green, white (Aslam } \\
\text { 2006; Kress and Leeuwen 2002; Mick 1986) }\end{array}$ & $\begin{array}{l}\text { Grey scale, red (Aslam 2006; Kress and } \\
\text { Leeuwen 2002; Mick 1986) }\end{array}$ \\
\hline \multicolumn{2}{|c|}{ Signs in the Environment } \\
\hline Positive & Negative \\
\hline $\begin{array}{l}\text { Health, happiness, smiles, hedonism } \\
\text { (Dillard and Anderson 2004; Hastings et al. } \\
\text { 2004: Lewis et al. 2007; Lewis et al. 2009) }\end{array}$ & $\begin{array}{l}\text { Death, fear, guilt, shame, desperation } \\
\text { (Brennan and Binney 2010; Cauberghe et al. } \\
\text { 2009; Dillard and Anderson 2004; Hastings et al. } \\
\text { 2004) }\end{array}$ \\
\hline \multicolumn{2}{|r|}{ Characters } \\
\hline Positive & Negative \\
\hline $\begin{array}{l}\text { Motivating/Confident people, social } \\
\text { models, testimonial, public figures } \\
\text { (Delbaere et al. 2011; Dillard and Anderson } \\
\text { 2004: Hastings et al. 2004; Lewis et al. 2007; } \\
\text { Lewis et al. 2009) }\end{array}$ & $\begin{array}{l}\text { Frightened/worried people (Brennan and } \\
\text { Binney 2010; Cauberghe et al. 2009: Dillard and } \\
\text { Anderson 2004; Hastings et al. 2004) }\end{array}$ \\
\hline
\end{tabular}

Fig. 1 Model to classify social advertisements as positive and negative appeals. Source: Casais and Proença, 2015 
Table 1 Frequency of social ads classified as negative, positive and combination of appeals

\begin{tabular}{|c|c|c|c|c|c|c|c|c|}
\hline \multirow[b]{2}{*}{ Countries } & \multicolumn{2}{|c|}{$\begin{array}{l}\text { Combina- } \\
\text { tion }\end{array}$} & \multicolumn{2}{|c|}{ Negative } & \multicolumn{2}{|c|}{ Positive } & \multicolumn{2}{|c|}{ Total } \\
\hline & $\mathrm{N}$ & $\%$ & $\mathrm{~N}$ & $\%$ & $\mathrm{~N}$ & $\%$ & $\mathrm{~N}$ & $\%$ \\
\hline France & 18 & 12.3 & 25 & 17.1 & 103 & 70.5 & 146 & 100.0 \\
\hline Germany & 6 & 5.2 & 22 & 19.1 & 87 & 75.7 & 115 & 100.0 \\
\hline Italy & 4 & 10.5 & 7 & 18.4 & 27 & 71.1 & 38 & 100.0 \\
\hline Portugal & 6 & 7.9 & 28 & 36.8 & 42 & 55.3 & 76 & 100.0 \\
\hline Total & 34 & 9.1 & 82 & 21.9 & 259 & 69.1 & 375 & 100.0 \\
\hline
\end{tabular}

Source: The authors

The high prevalence of positive appeals is evidenced in all the researched countries. The results contradict the state of the art that recognizes the popularity of negative appeals (Antonetti et al., 2015) and its effectiveness both in short and long time scales (Garg et al., 2021).

Despite the prominence of positive appeals, we observe oscillations across time, with ups and downs of the two message formats, which may be related to appeal direction weaknesses discussed in the literature (Brennan \& Binney, 2010; Slavin et al., 2007). We note in Fig. 2 that positive appeals had a higher prevalence over the time span, with the exception of 1992 and 1993, when negative appeals were more widely used, and 2001, with more combinations of appeals in social ads. This may be related to increasing numbers of infection, which required the use of fear appeals (Cooper et al., 2014; Ruiter et al., 2004), since there is relationship between social advertising and epidemic dynamics (Casais \& Proença, 2018). Those oscillations may also represent a reactive adaptation of social advertising to epidemic dynamics, such as the higher use of positive appeals after the introduction of anti-retroviral treatments (ART). The existence of a therapy may have led social marketing

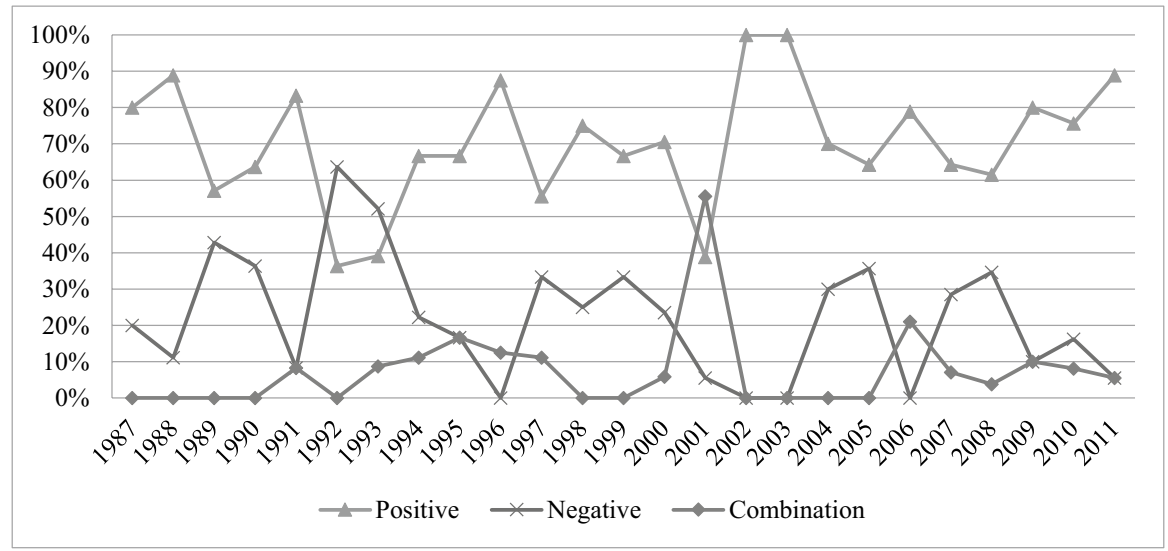

Fig. 2 Classification of Appeals in Social Advertisements by Year (\%). Source: The authors 
practitioners to choose messages of hope, showing the possibility of having quality of life and communicating that AIDS had become a chronic disease.

\subsection{Classification of Positive and Negative Appeals Used in Social Advertising}

Positive and negative appeals are combined, as suggested by OPM, but not in the same proportion, as highlighted in Table 2, which shows the distribution of category classifications by the final coding of ads according to the direction of appeals. The narrative was negative in $33.9 \%$ of the data. The categories with higher contributions to negative appeal ads are music/tonality of voice and environmental scenes, because of the importance of non-verbal signs for communicating shocking messages (Craton \& Lantos, 2011).

The social advertisements classified as positive appeals are supported by a high proportion of positive categories. The narrative category does not have a high influence in the final classification of the ads, but we note its importance in negative appeals. When the final classification of the ads was positive, $21.2 \%$ of those ads had a negative narrative about the disease (14.7\% of total data). The characters tend to be positive ( $69.3 \%$ of all data), but the present research shows that social marketers made little use of recruiting public figures to endorse the cause and promote coping response, in spite of their motivation to endorse HIV-prevention campaigns (Casais \& Proença, 2012). We found public figures as characters in $18.1 \%$ of the 375 social ads; $48.5 \%$ are from Germany and only $17 \%$ were coded as positive characters $(94.1 \%$ of celebrity endorsements). Animation films were also a technique used in $15.2 \%$ of the social ads analysed and tend to be classified as positive $(77.2 \%$ of cases).

Regarding regulatory focus theory, women were considered prevention-focused people for whom negative appeals would be more efficient (Gygax et al., 2010; Self $\&$ Findley, 2010). However, only 17 social ads were targeted at women and $82.4 \%$ were classified as positive appeals. Negative appeals are suggested by the literature to be more appropriate for low levels of perceived message response efficacy or perceived self-efficacy (Block \& Keller, 1995), although this is contradicted by other authors, who state the opposite (Peters et al., 2013). We considered in this case antidiscrimination social ads, general ads to stop or prevent AIDS and the promotion of adherence to treatment because of the secondary effects of therapy. Out of the 117 social ads with those messages, we found that only $36.8 \%$ were negative appeals. If we add the messages promoting condom use, which might be also considered as having low levels of perceived efficacy regarding the risk of ripping or tearing, we decrease the proportion of negative ads to $21.9 \%$ out of 338 social advertisements. These results show that social marketers have a strong preference for positive appeals.

We found that $69.8 \%$ of social advertisements developed by governmental institutions were classified as positive appeals. Considering the social ads developed by governments in partnership with non-governmental organizations (NGOs), the percentage increases to $70.7 \%$. Table 3 shows data distribution by classification of appeals and source institution, and shows that NGOs also tend to use positive appeal 


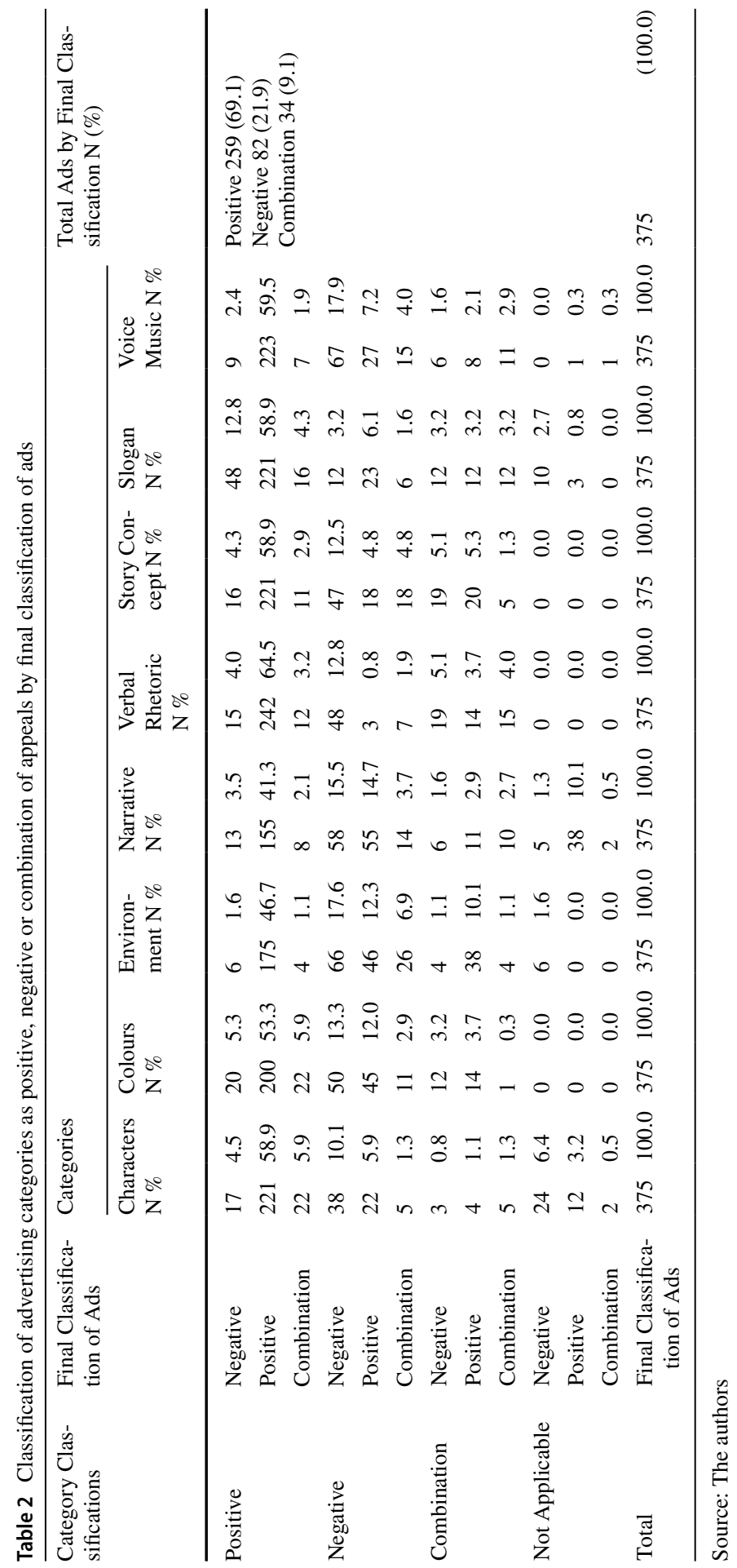


Table 3 Classification of social ads by appeal direction and source institution

\begin{tabular}{|c|c|c|c|c|c|c|c|c|}
\hline \multirow[b]{3}{*}{ Appeals } & \multicolumn{6}{|c|}{ Source Institution } & \multirow{2}{*}{\multicolumn{2}{|c|}{ Total }} \\
\hline & \multicolumn{2}{|c|}{ GOV. + NGO } & \multicolumn{2}{|c|}{ Governmental } & \multicolumn{2}{|c|}{ Non-Governmental } & & \\
\hline & $\mathrm{n}$ & $\%$ & $\mathrm{n}$ & $\%$ & $\mathrm{~N}$ & $\%$ & $\mathrm{~N}$ & $\%$ \\
\hline Combination & 0 & 0.0 & 18 & 4.8 & 16 & 4.3 & 34 & 9.1 \\
\hline Negative & 1 & 0.3 & 56 & 14.9 & 25 & 6.7 & 82 & 21.9 \\
\hline Positive & 10 & 2.7 & 171 & 45.6 & 78 & 20.8 & 259 & 69.1 \\
\hline Total & 11 & 2.9 & 245 & 65.3 & 119 & 31.7 & 375 & 100.0 \\
\hline
\end{tabular}

Source: The authors

advertisements, which is in line with recommendations from the literature (Hastings et al., 2004; Shin et al., 2017).

Culture influences effectiveness of appeals in advertising (Orth et al., 2007) and this research shows different proportional use of positive and negative appeals. Within the countries under research, Portugal had the highest proportion of negative advertisements, although representing just $36.8 \%$ of the HIV/AIDS-prevention social advertisements in that country and in lower proportion than positive appeals. This country also had relatively higher uncertainty avoidance (Hofstede, 2001). However, $82.1 \%$ of Portuguese negative advertisements were developed before 2001, representing $44.2 \%$ of all the analysed Portuguese data developed until that year. The period before 2001 represents the higher prevalence of patients with AIDS in Portugal, suggesting a connection between the seriousness of epidemics and use of negative appeals (Cooper et al., 2014; Ruiter et al., 2004).

Germany had the highest proportion of totally positive social advertisements and of the analysed countries it is the one with lower incidence rates. However, incidence rates had been increasing since 2001, and $81.8 \%$ of all German negative ads analysed were produced after that year. Negative advertisements represented 22.5\% of all German HIV/AIDS-prevention social ads that were produced from then until the end of 2011. Table 4 shows that there is a moderate positive correlation $(\rho \approx 0.4)$ between increasing rates of HIV incidence and the number of negative advertisements produced. The increasing trend of negative messages is associated with increasing rates of HIV incidence, although still in low proportion compared to positive appeals, which may be a reactive response to epidemics (Casais \& Proença, 2018).

On the other hand, the decreasing rates of HIV incidence in France, Portugal and Italy in the twenty-first century were negatively correlated with an increasing use of positive HIV-prevention advertisements, especially in Italy ( $\rho \approx-0.6$ ), as Table 5 shows. In fact, social advertising tends to fit epidemics and contextual factors (Casais \& Proença, 2018; Grassly et al., 2001).

Negative appeals may have a relationship with cultural concerns, as in the case of higher uncertainty avoidance in Portugal (Hofstede, 2001). This fact may have also been related to the concern of an epidemic situation in Portugal before the new millennium. The severity of epidemics might also have influenced the increasing use 
Table 4 Correlation coefficient between the number of german negative advertisements and German HIV incidence rates in the period 2001-2011

\begin{tabular}{llc}
\hline Year & German Negative Ads (n) & German HIV Incidence Rates \\
\hline 2001 & 1 & 1.8 \\
2004 & 1 & 2.7 \\
2005 & 3 & 3.0 \\
2007 & 2 & 3.4 \\
2008 & 8 & 3.5 \\
2009 & 2 & 3.5 \\
2011 & 1 & 3.5 \\
$n=7$ & Number of Ads $=18$ & Rates per 100.000 population \\
& & by year of diagnosis \\
0.40 & & \\
\hline
\end{tabular}

Sources: HIV/AIDS Surveillance in Europe 2011 (ECDC/WHO 2012); HIV/AIDS Surveillance in Europe 2010 (ECDC/WHO 2011); HIV/AIDS Surveillance in Europe 2009 (ECDC/WHO 2010)

Table 5 Correlation coefficients between the number of French, Portuguese and Italian positive advertisements and respective HIV incidence rates

\begin{tabular}{lrlll}
\hline Country & Period & Years (N) & $\begin{array}{l}\text { Positive } \\
\text { Ads }(\mathrm{N})\end{array}$ & $\rho$ \\
\hline France & $(2003-2011)$ & 9 & 46 & -0.18 \\
Portugal & $(2001 ; 2004-2011)$ & 9 & 19 & -0.19 \\
Italy & $(2005--2011)$ & 7 & 16 & -0.63 \\
\hline
\end{tabular}

Sources: HIV/AIDS Surveillance in Europe 2011 (ECDC/WHO 2012); HIV/AIDS Surveillance in Europe 2010 (ECDC/WHO 2011); HIV/AIDS Surveillance in Europe 2009 (ECDC/WHO 2010)

of negative appeals in Germany after 2001. When the incidence rates decrease, the study shows that social marketers increase the use of positive appeals, as proposed in the literature.

\section{Discussion}

The paper analysed the use of positive and negative emotional appeals in social advertising, through the observation of their frequency over time, how those appeals are manifested in the different components of television ads, and their fit with the contextual environment in a longitudinal overview - sensitiveness to the target audience, behaviour change message, type of institutional sources, cultural profiles, namely uncertainty avoidance and conservative levels of policy, as well as epidemic dynamics.

The results show an expressive predominance of positive social advertisements throughout time. Positive appeals are more frequent in motivational rhetoric and in active music or advising voice tonality. Some positive appeals take the form of 
animation films and include celebrity endorsers - few but increasing over time. This study concludes that, in opposition to the highly reported effectiveness of negative appeals in the background theory (Floyd et al., 2000; Garg et al., 2021; Hastings et al., 2004), positive social ads are predominant and have a much more expressive use throughout time. Social advertisements have also negative appeals in their components, although in lower proportion, especially in the narrative and signs of the scenes. We found an undulated cycle marked by an increasing and decreasing use of positive and negative appeals, but without affecting the preference of social marketers for positive messages. This may reflect the vulnerabilities of both message frames in terms of effectiveness. We did not find sensitiveness to factors previously reported in the literature that differentiate effectiveness of appeals, such as the target groups, the level of efficacy of the behaviour change messages or the type of source. In accordance with the previous literature, there is a connection between the use of positive and negative appeals, country profiles and seriousness of epidemics. Negative appeals were more frequent in Portugal until the end of the 1990's. It was a conservative society in that period and had higher relative uncertainty avoidance. There is a correlation between the increasing use of negative appeals in Germany in the early twenty-first century and the increasing incidence rates of infection in the same period. A similar sensitiveness is observed in the other analysed countries in this same period, especially in Italy. The increasing use of positive appeals is correlated with decreasing incidence rates of infection. In the use of positive and negative emotional appeals, sensitiveness to cultural aspects and epidemic dynamics reflect the background ideas that identify positive appeals as progressive and negative appeals as conservative but stronger and more effective messages used when incidence rates generate a more concerning epidemic situation (Hastings et al., 2004).

As social marketing practices do not show accordance with the conditions explored in the literature influencing and differentiating the effectiveness of positive and negative appeals in social ads, although the state of the art on the topic shows contradictory findings and inconsistencies, we wonder about possible barriers and trade-offs faced by public policy makers, since interventions are especially concentrated in the public sector. We further wonder whether the fact of HIV-prevention ads involving the discussion of fracturing issues, as well as stigma and discrimination linked to the disease and reported in the literature review (Castro et al., 2010), may concern social marketers and public policy makers, leading them to avoid targeting strong threat messages to the-most-at-risk populations and preferring incentives and not stigmatising positive appeals.

This paper gives contributions to both academics and policy makers. As the focus of the research consists in the analysis of practices, the recognition of practical specificities may be a contribution to enrich social marketing theory, based on the philosophy that theory is created with the insights of social practice (Spotswood et al., 2017). Given the theoretical incongruence of studies on the effectiveness of positive and negative appeals in social marketing, knowledge on the expressive use of positive appeals and how they are manifested in television social ads may reinforce their theoretical definition, characteristics and advantages as a motivating insight. Sensitiveness to culture and epidemic profiles also reinforces the theoretical evidences on the differences of effectiveness of appeals in different contexts. This understanding 
has managerial implications because it may be an important step to overcome constraints in practice and how theory is applied in social marketing (Levit \& Cismaru, 2020).

Particularly for public marketing, this research contributes with the evidence that social advertising should follow contextual conditions regarding culture and the target, but also the health issue, and calls for the discussion about whether social marketers analyse previous evidences of social marketing effectiveness. The particularities of public marketing operational processes, such as diversity of marketing suppliers and contract restrictions, have implications in a long-term advertising strategy that should include conscious options regarding the message frame of social ads. The study opens a further reflection on how the message frame is chosen in practice. Considering that advertising is also seen as a piece of art, sometimes designed to achieve advertising awards, it is important to reflect how copywriting and creativity reflect technical aspects of social marketing effectiveness regarding the direction of message frame.

\section{Conclusions}

In contrast with the recommendations of protection motivation theory, this paper shows the expressive use of positive appeals in the practice of social advertising. This was observed in the entire period under analysis, and was not connected with the diversity of target audience or the type of source organization. However, there is a wavy evolution, marked by increasing and decreasing rates over time, which may be related with the saturation of appeals and their vulnerabilities described in PMT and EPPM theories.

The study shows that social advertisements have both positive and negative appeals in their different components, although not in the same proportions. Motivating verbal rhetoric, positive music or an advising voice tonality are the advertising components which contribute more to a positive classification of the social ads. Narratives and signs from the scenes are the categories with more negative appeals. Some positive appeals take the form of animation films, but celebrity endorsements were few in number, though increasing.

The study suggests that there is appropriateness to country profiles and epidemic contexts. The increase of incidence rates is correlated with the use of negative ads and the decrease with positive advertisements. However, there is not a connection between the message frame used and the factors that differentiate the effectiveness of appeals in terms of the target groups following the regulatory focus theory, neither the level of efficacy of the behaviour change messages nor the type of source.

Given the theoretical incongruence of studies on the effectiveness of positive and negative appeals in social marketing communication, extant knowledge on the expressive use of positive appeals and how they are manifested in television social ads reinforce their function as a motivating insight for behaviour change. The paper has important implications for social marketing by highlighting that social marketers tend to choose positive appeals for social advertisements, regardless of target and context. Besides contributing to the theory of practice of social marketing, the 
results allow for a wider reflection on the gap between theory and practice that was found, such as the reasons for that phenomenon and the consequences in the evaluation of social marketing effectiveness. As public marketing is usually done by public contracts and involves different suppliers, a consistent strategy of message frame based on previous analysis of effectiveness may be difficult to apply. The results call for a deep discussion about how public marketing strategy is put into action, and whether it is based on advertising creativity or academic analysis of previous effectiveness.

The gap between theoretical knowledge and practice may reveal a concern with stigma and discrimination associated with this disease. It may indicate a pressure regarding the use of positive appeals, in motivating people to change without showing shocking images that might hurt people living with the infection or aggravate feelings of stigma in the wider society. This fact may influence the design of messages by social marketing practitioners. This understanding has managerial implications because it may be an important step to overcome constrains in practice and better design oriented interventions targeting vulnerable populations with the most effective appeals. The discussion of this trade-off may also be useful for the theory and practice of public policy, regarding the importance of evaluating the potential of their effectiveness through efficiency of the financial investments. Since society is a mirror of public policies, health-related social marketing impacts epidemic control and can be an important vehicle to fight illness stigma and discrimination.

\section{Limitations and Future Research}

The conclusions of the paper should consider the specificities of the case researched, such as the particular stigma and discrimination still faced by people living with HIV/AIDS. This study is also limited to the approach of the promotion dimension of social marketing mix regarding the specific case of television social advertisements. Due to the high volume of content analysis involved, the researchers took part in the coding process, and independent judges - paid for that specific task - coded a sample of data. The longitudinal amplitude of the research considered the first thirty years of infection diagnosis, considered the most concerning period of the disease lifecycle and deserving more attention from social marketers. However, data availability inhibited the researchers to conduct a deeper correlation analysis and comparisons between countries.

Future research might analyse other health-related social marketing themes in order to understand if positive appeals are a specificity of HIV/AIDS prevention. A wider number of countries in other global regions could be analysed. Other tools of the social marketing mix and other media besides social advertising on television may be explored, namely digital media. Future research may explore, through qualitative in-depth interviews, the consciousness of social marketing managers regarding the choice of positive and negative appeals, as well as the possible existence of trade-offs between theoretical effectiveness and the specificities of preventing a stigmatised disease. 
Acknowledgements Author João F. Proença gratefully acknowledges financial support from FCT - Fundação para a Ciência e Tecnologia (Portugal), national funding through research grant UID/ SOC/04521/2020.

\section{References}

Abroms, L. C., \& Maibach, E. W. (2008). The Effectiveness of Mass Communication to Change Behavior. Annual Review of Public Health, 29, 219-234.

Airhihenbuwa, C. O., \& Obregon, R. (2000). A Critical Assessment of Theories/Models Used in Health Communication for HIV/AIDS. Journal of Health Communication: International Perspectives, 5(supplement), 5-15.

Andreasen, A. R. (2002). Marketing Social Marketing in Social Change Marketplace. Journal of Public Policy \& Marketing, 21(1), 3-12.

Anghelcev, G., \& Sar, S. (2014). In the mood for [the right kind of] social marketing communication: How congruity between consumer mood and message framing influences intentions to recycle. Journal of Social Marketing, 4(1), 38-57.

Antonetti, P., Baines, P., \& Walker, L. (2015). From elicitation to consumption: Assessing the longitudinal effectiveness of negative emotional appeals in social marketing. Journal of Marketing Management, 31(9-10), 940-969.

Block, L. G., \& Keller, P. A. (1995). When to accentuate the negative: The effects of perceived efficacy and message framing on intentions to perform a health-related behavior. Journal of Marketing Research, 32(2), 192-203.

Boudewyns, V., Turner, M. M., \& Paquin, R. S. (2013). Shame-free guilt appeals: Testing the emotional and cognitive effects of shame and guilt appeals. Psychology \& Marketing, 30(9), 811-825.

Bourdieu, P. (1977). Outline of a theory of practice. Cambridge: Cambridge University Press.

Bourdieu, P. (1990). The logic of practice. Cambridge: Polity Press.

Brennan, L., \& Binney, W. (2010). Fear, guilt, and shame appeals in social marketing. Journal of Business Research, 63(2), 140-146.

Buyucek, N., Knox, K., \& Rundle-Thiele, S. (2019). A Positive Behavioral Approach: Identifying Theoretical Factors Influencing Moderate Drinking Practices. Social Marketing Quarterly, 25(2), $107-122$.

Campbell, R. G., \& Babrow, A. S. (2004). The role of empathy in responses to persuasive risk communication: Overcoming resistance to hiv prevention messages. Health Communication, 16(2), 159-182.

Cangelosi Jr., J. D., Ranelli, E., \& Markham, F. S. (2009). Who is making lifestyle changes due to preventive health care information? A demographic analysis. Health Marketing Quarterly, 26(2), 69-86.

Casais, B., \& Pereira, A. C. (2021). The Prevalence of emotional and rational tone in social advertising appeals. RAUSP Management Journal, 56(3), 282-294.

Casais, B., \& Proença, J. F. (2012). Inhibitions and implications associated with celebrity participation in health-related social marketing: An exploratory research focused on hiv prevention in portugal. Health Marketing Quarterly, 29(3), 206-222.

Casais, B., \& Proença, J. F. (2015). A model to classify television social advertisements according to their use of positive appeals. In I. Banks, P. DePelsmacker, \& S. Okazaki (Eds.), Advances in Advertising Research (Vol. V). Wiesbaden: Springer.

Casais, B., \& Proença, J. F. (2018). Social advertisements for public health and epidemic dynamics: A study based on hiv/aids prevention television advertisements in four european countries. Journal of Social Marketing, 8(4), 397-420.

Castro, D. R., Gall, J. M. L., Andreo, C., \& Spire, B. (2010). Stigma, discrimination, and sexual (dis) satisfaction among people living with HIV: results from the "AIDES et toi" survey. AIDS Care, 22(8), 961-969.

Cauberghe, V., Pelsmacker, P. D., Janssens, W., \& Dens, N. (2009). Fear, threat and efficacy in threat appeals: Message involvement as a key mediator to mesasge acceptance. Accident Analysis and Prevention, 41(2), 276-285.

Chan, K., Li, L., Diehl, S., \& Terlutter, R. (2007). Consumers' response to offensive advertising: a cross cultural study. International Marketing Review, 24(5), 606-628. 
Charry, K. M., \& Demoulin, N. T. M. (2012). Behavioural evidence for the effectiveness of threat appeals in the promotion of healthy food to children. International Journal of Advertising, 31(4), 773-794.

Chen, M.-F. (2016). Impact of fear appeals on pro-environmental behavior and crucial determinants. International Journal of Advertising, 35(1), 74-92.

Cheng, T., Woon, D. K., \& Lynes, J. K. (2011). The Use of Message Framing in the Promotion of Environmentally Sustainable Behaviors. Social Marketing Quarterly, 11(2), 48-62.

Chiang, K.-P., Chan, A., \& Milan, R. (2018). Social marketing and advertising appeals: On perception and intention to purchase condoms among college students. International Journal of Healthcare Management, 11(2), 71-78.

Cho, H., \& Salmon, C. T. (2007). Unintended effects of health communication campaigns. Journal of Communication, 57(2), 293-317.

Cook, J., Fries, S., \& Lynes, J. (2020). Checking Our Blind Spots: The Most Common Mistakes Made by Social Marketers. Social Marketing Quarterly, 26(1), 14-27.

Cooper, D. P., Goldenberg, J. L., \& Arndt, J. (2014). Perceived efficacy, conscious fear of death and intentions to tan: Not all fear appeals are created equal. British Journal of Health Psychology, 19(1), 1-15.

Craton, L. G., \& Lantos, G. P. (2011). Attitude toward the advertising music: an overlooked potential pitfall in commercials. Journal of Consumer Marketing, 28(6), 396-411.

Dickinson-Delaporte, S. J., \& Holmes, M. D. (2011). Threat appeal communications: The interplay between health resistance and cognitive appraisal processes. Journal of Marketing Communications, 17(2), 107-125.

Eppright, D. R., Hunt, J. B., TannerJr., J. F., \& Franke, G. R. (2003). Fear, coping, and information: A pilot study on motivating a healthy response. Health Marketing Quarterly, 20(1), 51-73.

Evans, W. D., \& McCormack, L. (2008). Applying social marketing in health care: Communicating evidence to change consumer behavior. Medical Decision Making, 28(5), 781-792.

Floyd, D. L., Prentice-Dunn, S., \& Rogers, R. W. (2000). A meta-analysis of research on protection motivation theory. Journal of Applied Social Psychology, 30(2), 407-429.

French, J. (2015). The importance of social marketing history. Social Marketing Quarterly, 21(4), 191-193.

French, J., \& Russell-Bennett, R. (2015). A hierarchical model of social marketing. Journal of Social Marketing, 5(2), 139-159.

Gallopel-Morvan, K., Gabriel, P., Gall-Ely, M. L., Rieunier, S., \& Urien, B. (2009). The use of visual warnings in social marketing: The case of tobacco. Journal of Business Research, 64(1), 7-11.

Gantiva, C., Jiménez-Leal, W., \& Urriago-Rayo, J. (2021). Framing messages to deal with the COVID-19 crisis: The role of loss/gain frames and content. Frontiers in Psychology, 12, 29.

Garg, N., Govind, R., \& Nagpal, A. (2021). Message framing effects on food consumption: A social marketing perspective. Australian Journal of Management, 46(4), 690-716.

Gomes, R. F., \& Casais, B. (2018). Feelings generated by threat appeals in social marketing: Text and emoji analysis of user reactions to anorexia nervosa campaigns in social media. International Review on Public and Nonprofit Marketing, 15(4), 591-607.

Good, A., \& Abraham, C. (2007). Measuring defensive responses to threatening messages: A meta-analysis of measures. Health Psychology Review, 1(2), 208-229.

Grassly, N. C., Garnett, G. P., Schwartländer, B., Gregson, S., \& Anderson, R. M. (2001). The effectiveness of HIV prevention and the epidemiological context. Bulletin of the World Health Organization, 79(12), 1121-1132.

Green, E. C., \& Witte, K. (2006). Can fear arousal in public health campaigns contribute to the decline of hiv prevalence? Journal of Health Communication, 11(3), 245-259.

Grier, S. A., \& Kumanyika, S. (2010). Targeted Marketing and Public Health. Annual Review of Public Health, 31(1), 349-369.

Griffin, D., \& O'Cass, A. (2004). Social marketing: Who really gets the message? Journal of Nonprofit \& Public Sector Marketing, 12(2), 129-147.

Gygax, P. M., Bosson, M., Gay, C., \& Ribordy, F. (2010). Relevance of health warnings in cigarette packs: A psycholinguistic investigation. Health Communication, 25(5), 397-409.

Hachfeld, A., Ledergerber, B., Darling, K., Weber, R., Calmy, A., Battegay, M., . . Stud, S. H. C. (2015). Reasons for late presentation to HIV care in Switzerland. Journal of the International AIDS Society, 18(1), 20317.

Hankins, C. A., \& Zalduondo, B. O. d. (2010). Combination prevention: a deeper understanding of effective HIV prevention. AIDS, 24(supl.4), 70-80 
Hartmann, P., Apaolaza, V., D’Souza, C., Barrutia, J. M., \& Echebarria, C. (2014). Environmental threat appeals in green advertising. International Journal of Advertising, 33(4), 741-765.

Hastings, G., \& Haywood, A. (1991). Social marketing and communication in health promotion. Health Promotion International, 6(2), 135-145.

Hastings, G., Stead, M., \& Webb, J. (2004). Fear appeals in social marketing: Strategic and ethical reasons for concern. Psychology \& Marketing, 21(11), 961-986.

Helmig, B., \& Thaler, J. (2010). On the effectiveness of social marketing-what do we really know? Journal of Nonprofit \& Public Sector Marketing, 22(4), 264-287.

Henley, N., \& Donovan, R. J. (1999). Threat appeals in social marketing: Death as a 'special case'. International Journal of Nonprofit and Voluntary Sector Marketing, 4(4), 300-319.

Higgins, E. T. (1997). Beyond pleasure and pain. American Psychologist, 52(12), 1280-1300.

Higgins, E. T. (1998). Promotion and prevention: regulatory focus as a motivational principle. In M. P. Zana (Ed.), Advances in Experimental Social Psychology (Vol. 30, pp. 1-46). New York: Academic Press.

Hill, R. P., \& Martin, K. D. (2014). Broadening the paradigm of marketing as exchange: A public policy and marketing perspective. Journal of Public Policy \& Marketing, 33(1), 17-33.

Hill, R. P., \& Morgan, N. (2011). Social marketing meets interactive media. International Journal of Advertising, 30(5), 815-838.

Hofstede, G. (2001). Culture's Consequences: Comparing Values, Behaviours, Institutions, and Organizations Across Nations (2 ed.). New York: McGraw-Hill.

Hornik, J., Ofir, C., \& Rachamim, M. (2017). Advertising appeals, moderators, and impact on persuasion. Journal of Advertising Research, 57(3), 305-318.

Jones, L. W., Sinclair, R. C., \& Courneya, K. S. (2003). The effects of source credibility and message framing on exercise intentions, behaviors, and attitudes: An integration of the elaboration likelihood model and prospect theory. Journal of Applied Social Psychology, 33(1), 179-196.

Jones, S. C., \& Owen, N. (2006). Using fear appeals to promote cancer screening - are we scaring the wrong people? International Journal of Nonprofit and Voluntary Sector Marketing, 11(2), 93-103.

Kahneman, D., \& Tversky, A. (1979). Prospect theory: An analysis of decision under risk. Econometrica, 47(2), 263-292.

Keller, P. A. (2006). Regulatory focus and efficacy of health messages. Journal of Consumer Research, 33(1), 109-114.

Keller, P. A., \& Lehmann, D. R. (2008). Designing effective health communications: A meta-analysis. Journal of Public Policy \& Marketing, 27(2), 117-130.

Laroche, M., Toffoli, R., Zhang, Q., \& Pons, F. (2001). A cross-cultural study of the persuasive effect of fear appeal messages in cigarette advertising: China and Canada. International Journal of Advertising, 20(3), 297-318.

Levit, T., \& Cismaru, M. (2020). Marketing social marketing theory to practitioners. International Review on Public and Nonprofit Marketing, 17, 237-252.

Lewis, I. M., Watson, B., White, K. M., \& Tay, R. (2007). Promoting public health messages: Should we move beyond fear-evoking appeals in road safety? Qualitative Health Research, 17(1), 61-74.

Li, X., Lin, C., Gao, Z., Stanton, B., Fang, X., Yin, Q., \& Wu, Y. (2004). HIV/AIDS knowledge and the implications for health promotion programs among Chinese college students: geographic, gender and age differences. Health Promotion International, 19(3), 345-356.

Likatavicius, G., \& VandeLaar, M. (2012). HIV and AIDS in the European Union, 2011. Eurosurveillance, 17(48), 20329.

Lwin, M. O., Stanaland, A. J. S., \& Chan, D. (2010). Using protection motivation theory to predict condom usage and asess hiv health communication efficacy in singapore. Health Communication, 25(1), 69-79.

Mattson, M., \& Basu, A. (2010). The message development tool: A case for effective operationalization of messaging in social marketing practice. Health Marketing Quarterly, 27(3), 275-290.

McKay-Nesbitt, J., Manchanda, R. V., Smith, M. C., \& Huhmann, B. A. (2011). Effects of age, need for cognition, and affective intensity on advertising effectiveness. Journal of Business Research, 64(1), $12-17$.

Meyerowitz, B. E., \& Chaiken, S. (1987). The effect of message framing on breast self-examination attitudes, intentions and behavior. Journal of Personality and Social Psychology, 52(3), 500-510.

Mukherjee, A., \& Dubé, L. (2012). Mixing emotions: The use of humor in fear advertising. Journal of Consumer Behaviour, 11(2), 147-161. 
Muralidharan, S., \& Sheeham, K. (2017). The role of guilt in influencing sustainable pro-environmental behaviors among shoppers. Journal of Advertising Research, 58(3), 349-362.

Muthusamy, N., Levine, T. R., \& Weber, R. (2009). Scaring the already scared: Some problems with hiv/aids fear appeals in namibia. Journal of Communication, 59(2), 317-344.

Myrick, J. G., \& Oliver, M. B. (2015). Laughing and crying: Mixed emotions, compassion, and the effectiveness of a youtube psa about skin cancer. Health Communication, 30(8), 820-829.

Noar, S. M., Palmgreen, P., Chabot, M., Dobransky, N., \& Zimmerman, R. S. (2009). A 10-year systematic review of hiv/aids mass communication campaigns: Have we made progress? Journal of Health Communication, 14(1), 15-42.

Noble, G., Pomering, A., \& Johnson, L. W. (2014). Gender and message appeal: Their influence in a proenvironmental social advertising context. Journal of Social Marketing, 4(1), 4-21.

O'Keefe, D. J., \& Jensen, J. D. (2008). Do loss-framed persuasive messages engender greater message processing than do gain-framed messages? A meta-analytic review. Communication Studies, 59(1), 51-67.

Orth, U. R., Koening, H. F., \& Firbasova, Z. (2007). Cross-national differences in consumer response to the framing or advertising messages: An exploratory comparison from central europe. European Journal of Marketing, 41(3/4), 327-348.

Paek, H.-j., Kim, K., \& Hove, T. (2010). Content Analysis of Antismoking videos on YouTube: message sensation value, message appeals, and their relationships with viewer responses. Health Education Research, 25(6), 1085-1099.

Palumbo, R. (2015). Discussing the effects of poor health literacy on patients facing HIV: A narrative literature review. International Journal of Health Policy and Management, 4(7), 417-430.

Peters, G.-J. Y., Ruiter, R. A. C., \& Kok, G. (2013). Threatening communication: A critical re-analysis and a revised meta-analytic test of fear appeal theory. Health Psychology Review, 7(S1), 8-31.

Pounders, K., Lee, S., \& Royne, M. (2018). The effectiveness of guilt and shame ad appeals in social marketing: The role of regulatory focus. Journal of Current Issues \& Research in Advertising, 39(1), 37-51.

Precourt, G. (2017). Why Television Still Matters. Journal of Advertising Research, 57(1), 1-2.

Prentice-Dunn, S., \& Rogers, R. W. (1986). Protection motivation theory and preventive health: Beyond the health belief model. Health Education Research, 1(3), 153-161.

Previte, J., Russel-Bennett, R., \& Parkinson, J. (2015). Shaping safe drinking cultures: Evoking positive emotion to promote moderate-drinking behaviour. International Journal of Consumer Studies, 30(1), $12-24$.

Quinn, G. P., Ellery, J., Thomas, K. B., \& Marshall, R. (2010). Developing a common language for using social marketing: An Analysis of public health literature. Health Marketing Quarterly, 27(4), 334-353.

Raftopoulou, E., \& Hogg, M. K. (2010). The Political Role of Government-Sponsored Social Marketing Campaigns. European Journal of Marketing, 44(7/8), 1206-1227.

Reardon, J., Miller, C., Foubert, B., Vida, I., \& Rybina, L. (2006). Antismoking messages for the international teenage segment: The effectiveness of message valence and intensity across different cultures. Journal of International Marketing, 14(3), 115-138.

Reckwitz, A. (2002). Toward a theory of social practices A development in culturalist theorizing. European Journal of Social Theory, 5(2), 243-263.

Rimal, R. N., Brown, J., Mkandawire, G., Folda, L., Böse, K., \& Creel, A. H. (2009). Audience segmentation as a social-marketing tool in health promotion: Use of the risk perception attitude framework in hiv prevention in malawi. American Journal of Public Health, 99(12), 2224-2229.

Robbins, R., \& Niederdeppe, J. (2019). Testing the role of narrative and gain-loss framing in messages to promote sleep hygiene among high school students. Journal of Health Communication, 24(1), 84-93.

Rosenstock, I. M. (1974). The health belief model and preventive health behavior. Health Education and Behavior, 2(4), 354-386.

Rothman, A. J., Salovey, P., Antone, C., Keough, K., \& Martin, C. D. (1993). The influence of message framing on intentions to perform health behaviors. Journal of Experimental Social Psychology, 29, 408-433.

Ruiter, R. A. C., Kessels, L. T. E., Peters, G. J. Y., \& Kok, G. (2014). Sixty years of fear appeal research: Current state of the evidence. International Journal of Psychology, 49(2), 63-70.

Ruiter, R. A. C., Verplanken, B., Cremer, D. D., \& Kok, G. (2004). Danger and fear control in response to fear appeals: The role of need for cognition. Basic and Applied Social Psychology, 26(1), 13-24.

Rust, R. T., \& Cooil, B. (1994). Reliability measures for qualitative data: Theory and implications. Journal of Marketing Research, 31(1), 1-14. 
Sar, S., \& Anghelcev, G. (2013). Perceived risk mediates the impact of mood on the effectiveness of health PSAs. Implications for public health marketing. Journal of Social Marketing, 3(1), 78-101.

Self, D. R., \& Findley, C. S. (2010). Sensation seekers as a healthcare marketing metasegment. Health Marketing Quarterly, 27(1), 21-47.

Shin, S., Ki, E.-J., \& Griffin, G. (2017). The effectiveness of fear appeals in 'green' advertising: An analysis of creative, consumer, and source variables. Journal of Marketing Communications, 23(5), 473-492.

Silva, S. C., \& Silva, M. F. (2012). Failure is a stepping stone for success. International Review on Public and Nonprofit Marketing, 9(2), 153-179.

Slavin, S., Batrouney, C., \& Murphy, D. (2007). Fear appeals and treatment side-effects: An effective combination for hiv prevention? AIDS Care, 19(1), 130-137.

Smerecnik, C. M. R., \& Ruiter, R. A. C. (2010). Fear appeals in hiv prevention: The role of anticipated regret. Psychology, Health \& Medicine, 15(5), 550-559.

Spigel, L. (2009). My TV Studies... Now Playing on a You Tube Site Near You. Television \& New Media, 10(1), 149-153.

Spotswood, F., Chatterton, T., Morey, Y., \& Spear, S. (2017). Practice-theoretical possibilities for social marketing: two fields learning from each other. Journal of Social Marketing, 7(2), 156-171.

Tan, N. Q. P., \& Cho, H. (2019). Cultural appropriateness in health communication: A review and a revised framework. Journal of Health Communication, 24(5), 492-502.

Teng, L., Zhao, G., Li, F., Liu, L., \& Shen, L. (2019). Increasing the persuasiveness of anti-drunk driving appeals: The effect of negative and positive message framing. Journal of Business Research, 103(October), 240-249.

Teng, L., Zhao, G., Wu, Y., Fu, H., \& Wang, J. (2019). Positive versus negative messaging in discouraging drunken driving matching behavior consequences with target groups. Journal of Advertising Research, 59(2), 185-195.

Terblanche-Smit, M., \& Terblanche, N. S. (2010). Race and attitude formation in hiv/aids fear advertising. Journal of Business Research, 63(2), 121-125.

Tversly, A., \& Kahneman, D. (1981). The framing of decisions and the psychology of choice. Science, 211(4481), 453-458.

Vega, M. Y., \& Roland, E. L. (2005). Social marketing techniques for public health communication: A review of syphilis awareness campaigns in 8 US Cities. Sexually Transmitted Diseases, 32(10), S30-S36.

Vincent, A.-M., \& Dubinsky, A. J. (2005). Impact of fear appeals in a cross-cultural context. Journal of Euromarketing, 14(1), 145-167.

Vos, S. d., Crouch, R., Quester, P., \& Ilicic, J. (2017). Examining the effectiveness of fear appeals in prompting help-seeking: The case of at-risk gamblers. Psychology \& Marketing, 34(6), 648-660.

Wang, C. X., Minton, E. A., \& Zhang, J. (2020). Sense of power: Policy insights for encouraging consumers' healthy food choice. Journal of Public Policy \& Marketing, 39(2), 188-204.

Wettstein, D., \& Suggs, L. S. (2016). Is it social marketing? The benchmarks meet the social marketing indicator. Journal of Social Marketing, 6(1), 2-17.

Witte, K. (1992). Putting the fear back into fear appeals: The extended parallel processing model. Communication Monographs, 59(4), 329-349.

Witte, K. (1994). Fear Control and Danger Control: a test of the extended parallel process model (EPPM). Communication Monographs, 61(2), 113-134.

Witte, K., \& Allen, M. (2000). A meta-analysis of fear appeals: Implications for effective public health campaigns. Health Education and Behavior, 27(5), 591-615.

Xu, J., \& Huang, G. (2020). The relative effectiveness of gain-framed and loss-framed messages in charity advertising: Meta-analytic evidence and implications. International Journal of Nonprofit and Voluntary Sector Marketing, 25(4), e1675.

Yoon, H. J., \& Tinkham, S. F. (2013). Humorous threat persuasion in advertising: The effects of humor, threat intensity, and issue involvement. Journal of Advertising, 42(1), 30-41.

Zhao, G., \& Pechmann, C. (2007). The impact of regulatory focus on adolescents' response to antismoking advertising campaigns. Journal of Marketing Research, 44(4), 671-683.

Publisher's note Springer Nature remains neutral with regard to jurisdictional claims in published maps and institutional affiliations. 


\section{Authors and Affiliations}

\section{Beatriz Casais $^{1}$ (ID $\cdot$ João F. Proença ${ }^{2,3}$}

1 School of Economics and Management, and CICS.NOVA.UMinho, University of Minho, Campus de Gualtar, 4710-057 Braga, Portugal

2 Faculty of Economics, University of Porto, Porto, Portugal

3 Advance/CSG, ISEG, University of Lisbon, Lisboa, Portugal 